\title{
ATRIBUTOS FÍSICOS DE UM ARGISSOLO EM SISTEMAS DE CULTURAS DE LONGA DURAÇÃO SOB SEMEADURA DIRETA $^{(1)}$
}

\author{
Mastrângello Enívar Lanzanova ${ }^{(2)}$, Flávio Luiz Foletto Eltz ${ }^{(3)}$, \\ Rodrigo da Silveira Nicoloso ${ }^{(4)}$, Telmo Jorge Carneiro \\ Amado $^{(5)}$, Dalvan José Reinert ${ }^{(3)} \&$ Marta Rodrigues da \\ $\operatorname{Rocha}^{(6)}$
}

\begin{abstract}
RESUMO
O sistema de semeadura direta, associado à utilização de plantas de cobertura, pode manter a qualidade do solo, melhorando e, ou, preservando seus atributos físicos em condições favoráveis ao desenvolvimento vegetal. O presente trabalho avaliou a densidade, porosidade, resistência à penetração e taxa de infiltração de água em um Argissolo Vermelho distrófico arênico, na área experimental do Departamento de Solos da Universidade Federal de Santa Maria, em Santa Maria, RS, após 16 anos de aplicação de sete sistemas de culturas: (1) milho (Zea mays L.) + feijão-de-porco (Canavalia ensiformis DC)/soja (Glycine max (L.) Merr.)- MFP; (2) solo descoberto - SDES; (3) milho/pousio/soja - POU; (4) milho/azevém (Lolium multiflorum Lam.) + ervilhaca-comum (Vicia sativa)/soja - AZEV; (5) milho + mucuna-cinza (Stizolobium cinereum)/soja - MUC; (6) $\mathrm{milho} / \mathrm{nabo}$ forrageiro (Raphanus sativus L. var. oleiferus Metzg.)/soja - NFO; e (7) campo nativo - CNA. A densidade do solo apresentou diferenças entre os tratamentos até a profundidade de $0,10 \mathrm{~m}$, com o SDES evidenciando maiores valores. A porosidade total e a macroporosidade do solo apresentaram estreita relação entre si até $0,10 \mathrm{~m}$ de profundidade. $\mathrm{O}$ tratamento SDES apresentou maior resistência à penetração na camada superficial (até $0,03 \mathrm{~m}$ ), e o NFO, nas profundidades de 0,16 e 0,18 m. Menores taxas de infiltração de água no solo foram verificadas nos tratamentos
\end{abstract}

\footnotetext{
(1) Parte da Tese de Doutorado do primeiro autor apresentada ao Programa de Pós-Graduação em Engenharia Agrícola da Universidade Federal de Santa Maria, RS. Recebido para publicação em agosto de 2009 e aprovado em junho de 2010.

(2) Professor Assistente da Universidade Estadual do Rio Grande do Sul - UERGS. Polo Três Passos (RS). Rua Cipriano Barata 47, CEP 98600-000 Três Passos (RS). E-mail: mastrangello-lanzanova@uergs.edu.br

(3) Professor Titular do Departamento de Solos, Universidade Federal de Santa Maria - UFSM. Av. Roraima 1000, Camobi, CEP 97105-900 Santa Maria (RS).E-mail: feltz@ccr.ufsm.br, dalvan@ccr.ufsm.br

(4) Pesquisador em Pós-Doutorado (CAPES-PNPD), Departamento de Solos, UFSM. E-mail: nicoloso@live.com

(5) Professor Associado do Departamento de Solos, UFSM. E-mail: tamado@ccr.ufsm.br

(6) Mestrando do Programa de Pós-Graduação em Ciência do Solo, UFSM. Bolsista CAPES. E-mail: martadarocha@mail.ufsm.br
} 


\begin{abstract}
SDES e CNA, enquanto os demais se mantiveram constantemente acima destes e semelhantes entre si. O sistema de semeadura direta com uso de plantas de cobertura do solo mostrou-se eficiente em manter atributos físicos em condições favoráveis ao desenvolvimento vegetal, após longo período de utilização, ao mesmo tempo em que melhorou atributos como a taxa de infiltração de água.
\end{abstract}

Termos de indexação: compactação do solo, porosidade, infiltração de água, plantas de cobertura, leguminosas tropicais, nabo forrageiro.

\title{
SUMMARY: PHYSICAL PROPERTIES OF A TYPIC PALEUDALF UNDER LONG-TERM NO-TILLAGE AND CROPPING SYSTEMS
}

\begin{abstract}
No-tillage associated to cover crops may maintain soil quality, improving or preserving favorable soil physical conditions for plant growth. This study assessed soil bulk density, porosity, penetration resistance, and water infiltration of a PALEUDALF, in the Experimental Area of the Soil Science Department of the Federal University of Santa Maria, in Santa Maria, $R S$, Brazil, in an experiment started in 1991, with the following crop successions and rotations: (1) Corn/Soybean - Jackbean - MFP; (2) Bare soil - SDES; (3) Corn/Soybean - Fallow POU; (4) Corn/Soybean - Ryegrass + Vetch - AZEV; (5) Corn /Soybean - Mucuna - MUC; (7) Natural Grass - CNA; (6) Corn/Soybean - Oilseed radish - NFO. Soil bulk density was affected in the 0-0.10 m layer; values were highest in the SDES. Total soil porosity and soil macroporosity were closely correlated to a depth of $0.10 \mathrm{~m}$. Major restriction to root penetration occurred in the surface layer $(0-0.03 \mathrm{~m})$ in the SDES treatment, and NFO had greatest values at 0.16-0.18 m depth. The water infiltration rate was lowest in SDES and CNA treatments in all evaluations, while in the others infiltration was constant and statistically equal. Constantly uncovered soil induces degradation in soil physical properties. The studied cropping systems confirmed significant benefits in soil density, porosity, resistance, and water infiltration rate under long term no-tillage.
\end{abstract}

Index terms: soil compaction, porosity, water infiltration, cover crops, tropical legumes, oilseed radish.

\section{INTRODUÇÃO}

A degradação física é uma das principais causas da baixa produtividade dos solos agrícolas. O adensamento do solo, que corresponde ao aumento da sua densidade, é frequentemente verificado na camada superficial de solos manejados sob sistema de semeadura direta (SSD), comparativamente àqueles manejados sob sistema de preparo convencional (SPC) (Pierce et al., 1994). No entanto, esse adensamento geralmente não ocorre em profundidade (Prado et al., 2002).

Apesar de mais denso na superfície, o solo sob SSD apresenta maior taxa de infiltração e retenção de água e menor escoamento superficial (Alves \& Cabeda, 1999), devido à maior continuidade e estabilidade dos bioporos e macroporos e à maior estabilidade estrutural (Lal \& Vandoren, 1990). No entanto, esses atributos de solo apresentam grande variabilidade espacial, em função de condições ambientais, tipos e tamanhos (massa) de máquinas e equipamentos e sistemas de culturas utilizados (Reichert et al., 2003). O aumento do conteúdo de matéria orgânica do solo sob SSD também contribui para a melhoria dos atributos físicos do solo, reduzindo a densidade média das partículas, aumentando a macroporosidade e, consequentemente, reduzindo a densidade do solo e aumentando a taxa de infiltração de água e a sua resistência à compactação (Nicoloso et al., 2008b).

Sistemas de culturas que envolvem adubos verdes de verão e de inverno em rotação com culturas produtoras de grãos, em especial soja e milho, proporcionam ao mesmo tempo um aporte constante e diferenciado de resíduos vegetais ao solo e favorecem a manutenção de uma melhor condição física deste para o desenvolvimento das plantas (Cintra \& Meilniczuk, 1983). Por outro lado, sistemas em que o pousio invernal é adotado, ou sistemas em que o solo permaneça descoberto durante um período significativo, promovem a exposição aos agentes erosivos, que conduzem à degradação do solo, com consequente queda de produtividade das culturas. Quando o solo é exposto diretamente ao impacto das gotas de chuva, verifica-se a formação de crosta superficial, a qual provoca diminuição significativa na sua taxa de infiltração de água e favorece o escoamento superficial de água e consequente processo de erosão. Além disso, provoca também aumento na 
sua densidade, diminuindo significativamente sua porosidade, sobretudo a macroporosidade, responsável pela aeração do solo e por boa parte da infiltração de água (Silva \& Kato, 1997). Adicionalmente, mesmo um solo sendo manejado sob SSD, porém com baixa adição de resíduos culturais e pouca cobertura de solo, pode apresentar redução de sua porosidade, incremento de densidade e encrostamento superficial (Bolliger et al., 2006).

Espécies de adubos verdes de verão, como o feijãode-porco e a mucuna, e de inverno, como nabo forrageiro, azevém e ervilhaca, contribuem com elevada produção de matéria seca, reduzindo as perdas de solo por erosão, por mantê-lo permanentemente protegido. No caso das leguminosas, também ocorre a fixação biológica de $\mathrm{N}$ - elemento essencial a todas as culturas de interesse econômico na agricultura (Silva et al., 2007). Rosolem et al. (2002) destacaram o potencial de plantas de cobertura do solo para serem utilizadas em sistemas de rotação de culturas, com o objetivo de melhorar a qualidade física de solos compactados. Willians \& Well (2004) verificaram que as raízes do nabo forrageiro, após a sua senescência (morte e decomposição), formaram canais no solo e que as raízes da soja cultivada em subsequência apresentaram crescimento preferencial nesses canais, facilitando seu aprofundamento no perfil e a exploração de maior volume de solo. Foloni et al. (2006), avaliando o crescimento aéreo e radicular da soja e de plantas de cobertura em camadas de solo compactadas, concluíram que, entre várias espécies de leguminosas de verão, a mucuna-preta foi a mais tolerante ao efeito nocivo da compactação, enquanto a soja foi a mais sensível a esse efeito. Nicoloso et al. (2008a) encontraram, em um Latossolo, aumento na macroporosidade do solo, diminuição na resistência à penetração e incrementos na infiltração de água quando da utilização do consórcio nabo forrageiro + aveia-preta.

Buscando estabelecer limites críticos de densidade do solo para o crescimento de raízes de plantas de cobertura, num Argissolo Vermelho semelhante ao do presente estudo, Reinert et al. (2008) concluíram que todas as espécies de adubos verdes avaliadas (crotalária juncea, guandu-anão, feijão-de-porco e mucuna-cinza) poderiam ser utilizadas em solos com compactação excessiva. No entanto, com densidade superior a $1,85 \mathrm{Mg} \mathrm{m}^{-3}$, a utilização da escarificação mecânica ou subsolagem pode ser necessária. Embora os benefícios da inserção dessas plantas em sistemas de culturas sejam conhecidos, a sua efetiva adoção por parte dos produtores rurais é ainda diminuta, principalmente das espécies de ciclo de verão, pois elas competem por área com as principais culturas econômicas, como a soja (Foloni et al., 2006).

Informações geradas a partir de experimentos de longa duração são ferramentas valiosas na comprovação dos efeitos benéficos dessas espécies, sobretudo no que diz respeito às propriedades físicas e à melhoria da qualidade do solo, contribuindo para a sua adoção.
Este trabalho teve como objetivo verificar as alterações ocorridas nos atributos físicos de um Argissolo Vermelho textura franco-arenosa após 16 anos de SSD sem o trânsito de máquinas agrícolas, com distintos sistemas de culturas de cobertura de verão e inverno, em rotação com a soja e o milho, comparando-os com os de solo mantido permanentemente descoberto e um campo nativo.

\section{MATERIAL E MÉTODOS}

Este estudo foi realizado em área do Departamento de Solos da Universidade Federal de Santa Maria, município de Santa Maria, região fisiográfica da Depressão Central do Estado do Rio Grande do Sul, e faz parte de um experimento de perdas de solo e água de longa duração que teve início no ano de 1991. Os resultados aqui apresentados foram obtidos nos anos de 2007 e 2008. O clima da região é do tipo subtropical úmido, Cfa segundo a classificação de Köppen, com precipitação pluvial e temperatura média anual de $1.500 \mathrm{~mm}$ e $18,5^{\circ} \mathrm{C}$, respectivamente (Brasil, 1973). O solo característico do local é classificado como Argissolo Vermelho distrófico arênico (Embrapa, 1999). O experimento foi instalado sobre área que era mantida sob pastagem nativa, com predomínio de espécies gramíneas de estação quente, que apresentava na camada de 0-0,20 $\mathrm{m}$ de profundidade, antes da sua instalação, os seguintes valores de granulometria e fertilidade do solo: $87 \mathrm{~g} \mathrm{~kg}^{-1}$ de argila; $660 \mathrm{~g} \mathrm{~kg}^{-1} \mathrm{de}$ areia total; $253 \mathrm{~g} \mathrm{~kg}^{-1}$ de silte; $\mathrm{pH}-\mathrm{H}_{2} \mathrm{O}=4,50 ; \mathrm{P}=$ $1,80 \mathrm{mg} \mathrm{dm}^{-3} ; \mathrm{K}=33 \mathrm{mg} \mathrm{dm}{ }^{-3} ; \mathrm{MO}=24,6 \mathrm{~g} \mathrm{~kg}^{-1} ; \mathrm{Al}$ $=1,4 \mathrm{cmol}_{\mathrm{c}} \mathrm{kg}^{-1} ; \mathrm{Ca}+\mathrm{Mg}=2,6 \mathrm{cmol}_{\mathrm{c}} \mathrm{kg}^{-1} ;$ CTC efetiva $=4,08 \mathrm{cmol}_{\mathrm{c}} \mathrm{dm}^{-3}$; e saturação por $\mathrm{Al}=34,31 \mathrm{~g} \mathrm{~kg}^{-1}$ (Debarba, 1993).

O delineamento experimental foi o inteiramente casualizado, com sete tratamentos e duas repetições. Cada parcela experimental foi delimitada por chapas de aço galvanizado com $0,20 \mathrm{~m}$ de altura, introduzidas no solo a uma profundidade de $0,10 \mathrm{~m}$. As dimensões de cada parcela foram de 3,5 m de largura e 22,0 m de comprimento, com declividade média de $0,055 \mathrm{~m} \mathrm{~m}^{-1}$. Mais detalhes sobre o experimento podem ser obtidos em Debarba (1993) e Seganfredo (1995).

Os tratamentos corresponderam aos seguintes sistemas de culturas: (1) milho (Zea mays L.) + feijãode-porco (Canavalia ensiformis DC)/soja (Glycine max (L.) Merr.) - MFP; (2) solo descoberto - SDES; (3) milho/ pousio/soja - POU; (4) milho/azevém (Lolium multiflorum Lam.) + ervilhaca-comum (Vicia sativa)/ soja-AZEV; (5) milho + mucuna-cinza (Stizolobium cinereum)/soja - MUC; (6) milho/nabo forrageiro (Raphanus sativus L. var. oleiferus Metzg.)/soja NFO; e (7) campo nativo - CNA. Esses sistemas de cultura, que foram idealizados visando à utilização em pequenas propriedades sem disponibilidade de tração mecanizada, vêm sendo adotados desde o ano de 2001; detalhes da descrição da sequência de culturas 
anteriormente utilizadas podem ser encontrados em Lanzanova (2009).

As culturas de soja e milho foram semeadas com semeadora manual (saraquá), enquanto o feijão-deporco e a mucuna foram semeados em sulcos abertos com enxada nas entrelinhas da cultura do milho. Essas operações foram realizadas transversalmente ao sentido da declividade. As quantidades de sementes utilizadas para o feijão-de-porco e para a mucuna foram de 60 e $40 \mathrm{~kg}$ por hectare, respectivamente, e seguiram as recomendações técnicas para o seu cultivo consorciado com o milho. As culturas de azevém, ervilhaca e nabo forrageiro foram semeadas manualmente a lanço sobre a resteva da cultura anterior, nas quantidades de 20,30 e $20 \mathrm{~kg}$ de sementes por hectare, respectivamente, seguindo a recomendação para cada espécie. As adubações utilizadas para as culturas da soja e milho seguiram as recomendações da Comissão de Fertilidade do Solo - CFSRS/SC (2004) para obtenção de elevadas produtividades e foram sempre realizadas a lanço na superfície do solo. Os demais tratos culturais aplicados tanto na cultura da soja quanto na do milho seguiram as recomendações técnicas vigentes para o Estado do Rio Grande do Sul. As demais culturas não receberam nenhum tipo de adubação, e o manejo final, por meio de dessecação com herbicidas, foi realizado no início do mês de outubro de cada ano de condução do trabalho, coincidindo com a fase de pleno florescimento das culturas. As parcelas mantidas em pousio invernal foram dessecadas com herbicidas após a colheita de grãos das culturas de verão, permanecendo assim até o momento do plantio da nova cultura de verão. Após a colheita de grãos de milho, a mucuna e o feijão-deporco continuaram se desenvolvendo até que a ocorrência de frio intenso interrompesse seus ciclos. Todas as operações de manejo, desde semeadura, aplicação de produtos químicos e colheita, foram realizadas manualmente e com auxílio de ferramentas normalmente usadas em agricultura de pequena propriedade.

Em outubro de 2007, após o cultivo das plantas de cobertura de inverno, foi realizada a avaliação da resistência mecânica do solo à penetração $(\mathrm{RP})$ na camada de 0,0-0,30 $\mathrm{m}$ de profundidade, em incrementos de $0,01 \mathrm{~m}$, num total de 20 repetições por tratamento. O equipamento utilizado nessa avaliação foi um penetrômetro digital com ponta cônica de $30^{\circ}$, que foi introduzido manualmente no solo. Concomitantemente a essa avaliação, também foi determinada a umidade gravimétrica do solo, em três camadas $(0-0,10,0,10-0,20$ e $0,20-0,30 \mathrm{~m})$ e quatro repetições por tratamento.

Na mesma época em que foram feitas as avaliações de RP, também foi determinada a taxa de infiltração de água no solo, pelo método dos duplos anéis concêntricos, descrito em Embrapa (1997). Para medir o volume de água infiltrado no anel interno, utilizouse um aparelho confeccionado com um cano de PVC de 0,15 m de diâmetro e 1,0 m de comprimento, dotado de um piezômetro fixado sobre uma régua graduada em mililitros, que permitiu medir a variação do volume/lâmina de água entre observações. O referido aparelho está descrito detalhadamente em Lanzanova (2005). O ajuste dos dados de infiltração de água no solo foi realizado segundo a equação de Kostiakov $\left(\mathrm{TI}=\mathrm{kt}^{-\mathrm{a}}\right)$, em que TI representa a taxa de infiltração de água no solo, em função do tempo $t$; os parâmetros $k$ e $a$ são empíricos e não têm interpretação física. Foram realizadas 10 repetições por tratamento, com duração de duas horas cada.

Após a colheita da cultura do milho, em maio de 2008 , foram realizadas duas coletas de amostras indeformadas por parcela experimental, nas camadas de $0,0-0,05,0,05-0,10,0,10-0,15$ e $0,15-0,20 \mathrm{~m}$ de profundidade, com o auxílio de anéis de aço com volume conhecido, totalizando quatro repetições por tratamento em cada camada. Em laboratório, foram determinadas a densidade do solo (Ds), pelo método do anel volumétrico; a porosidade total (Pt), pela percentagem de saturação de água do solo; e a microporosidade (Mi) e macroporosidade do solo (Ma), pelo método da mesa de tensão (Embrapa, 1997).

Os resultados foram avaliados por meio da análise de variância e aplicação do teste de Tukey a 5 \% para comparação de médias dos tratamentos. A relação entre a taxa de infiltração de água no solo e a macroporosidade foi efetuada por análise de regressão linear, com auxílio do pacote estatístico SAS.

\section{RESULTADOS E DISCUSSÃO}

No quadro 1, são apresentados os resultados das avaliações de densidade (Ds), porosidade total, macro e microporosidade do solo, determinadas um ano após a instalação do experimento. Os resultados das mesmas avaliações efetuadas em amostras coletadas 16 anos após a instalação do experimento são apresentados no quadro 2 . Por terem sido realizadas amostragens em diferentes camadas de solo, no início do experimento (Quadro 1) e 16 anos após (Quadro 2), a comparação direta dos tratamentos entre épocas não foi realizada. Como o solo da área foi uniformizado com uma aração e duas gradagens quando da instalação do experimento (antes da implantação das culturas), os resultados das avaliações não diferiram significativamente entre os tratamentos naquela coleta (Quadro 1).

Já em 2008, a Ds mostrou alterações significativas até a profundidade de 0,10 m, com o tratamento SDES apresentando valor maior que o dos demais nas camadas de 0-0,05 e 0,05-0,10 m, porém nesta última não diferindo dos tratamentos POU, AZEV, MUC e NFO. Resultado semelhante foi encontrado por Frye et al. (1982), que também observaram maiores valores de Ds onde houve erosão, em dois solos dos Estados 
Quadro 1. Densidade do solo (DS), porosidade total (Pt), macroporosidade (Ma) e microporosidade do solo (Mi) nas camadas de $0,00-0,08$ e 0,08 0,16 m de um Argissolo Vermelho submetido a diferentes sistemas de culturas em plantio direto, no primeiro ano do experimento

\begin{tabular}{|c|c|c|c|c|}
\hline Tratamento $^{(1)}$ & Ds & $\mathbf{P t}$ & Ma & Mi \\
\hline & $\mathrm{Mg} \mathrm{m}^{-3}$ & \multicolumn{3}{|c|}{$-\mathrm{m}^{3} \mathrm{~m}^{-3}$} \\
\hline & & \multicolumn{3}{|c|}{$0,00-0,08 \mathrm{~m}$} \\
\hline MFP & $1,40^{\mathrm{ns}}$ & $0,49^{\text {ns }}$ & $0,20^{\mathrm{ns}}$ & $0,28^{\mathrm{ns}}$ \\
\hline SDES & 1,44 & 0,47 & 0,19 & 0,28 \\
\hline POU & 1,46 & 0,47 & 0,17 & 0,30 \\
\hline AZEV & 1,40 & 0,48 & 0,19 & 0,30 \\
\hline MUC & 1,40 & 0,49 & 0,20 & 0,29 \\
\hline CNA & 1,61 & 0,42 & 0,12 & 0,29 \\
\hline \multirow[t]{2}{*}{ NFO } & 1,45 & 0,47 & 0,22 & 0,26 \\
\hline & & \multicolumn{3}{|c|}{$0,08-0,16 \mathrm{~m}$} \\
\hline $\mathrm{FP}$ & $1,48^{\mathrm{ns}}$ & $0,46^{\text {ns }}$ & $0,18^{\text {ns }}$ & $0,28^{\text {ns }}$ \\
\hline SDES & 1,58 & 0,42 & 0,13 & 0,29 \\
\hline POU & 1,52 & 0,45 & 0,15 & 0,30 \\
\hline AZEV & 1,52 & 0,45 & 0,15 & 0,28 \\
\hline MUC & 1,48 & 0,44 & 0,15 & 0,29 \\
\hline $\mathrm{CNA}$ & 1,51 & 0,45 & 0,14 & 0,31 \\
\hline NFO & 1,51 & 0,45 & 0,18 & 0,27 \\
\hline
\end{tabular}

(1) MFP: milho + feijão-de-porco/soja; SDES: solo descoberto; POU: milho/pousio/soja; AZEV: milho/azevém + ervilhaca/soja; MUC: milho + mucuna/soja; CNA: campo nativo; NFO: milho/ nabo forrageiro/soja. Adaptado de Debarba (1993). ${ }^{\text {ns: }}$ diferenças não significativas pelo teste de Tukey $(\mathrm{p}<0,05)$.

Unidos, em comparação com os mesmos solos não erodidos. A comparação dos resultados obtidos nos tratamentos dentro de cada camada de solo deve ser cuidadosamente avaliada, uma vez que, nas parcelas que mantiveram o solo descoberto, uma camada de aproximadamente $0,16 \mathrm{~m}$ foi removida da superfície pela erosão durante 16 anos de condução do experimento. Nos demais tratamentos também foram verificadas perdas de solo, porém em níveis inferiores a $0,5 \%$ do valor encontrado no tratamento SDES. Dessa maneira, pode-se inferir que a camada de 0,0 $0,05 \mathrm{~m}$ da última coleta no SDES corresponde à camada de aproximadamente $0,15-0,20 \mathrm{~m}$ dos demais tratamentos. Contudo, os resultados do quadro 2 indicam que a partir de $0,10 \mathrm{~m}$ de profundidade não há diferenças entre os valores de densidade e porosidade do solo entre os tratamentos, ou seja, os efeitos dos sistemas de culturas ficaram restritos aos primeiros 0,10 m de profundidade. Como no tratamento SDES não eram cultivadas plantas, outro fator deve ter atuado na superfície do solo no sentido de promover adensamento ou compactação. Segundo Silva \& Kato (1997), o efeito do impacto das gotas da chuva na promoção do selamento superficial constitui-se num fenômeno que ocorre em uma camada muito delgada, de poucos milímetros, mas com efeitos significativos no aumento da densidade, resistência à penetração, diminuição da taxa de infiltração e compactação do solo.
Quadro 2. Densidade do solo (Ds), porosidade total (Pt), macroporosidade (Ma) e microposoridade (Mi) nas camadas de $0-0,05,0,05-0,10,0,10-0,15$ e 0,15-0,20 m de um Argissolo Vermelho submetido a diferentes sistemas de culturas em plantio direto, após 16 anos de experimentação

\begin{tabular}{|c|c|c|c|c|}
\hline Tratamento $^{(1)}$ & Ds & $\mathbf{P t}$ & Ma & Mi \\
\hline & \multicolumn{4}{|c|}{$0,00-0,05 \mathrm{~m}$} \\
\hline MFP & $1,17 \mathrm{~b}^{(1)}$ & $0,53 \mathrm{a}$ & $0,26 \mathrm{a}$ & $0,26 \mathrm{ab}$ \\
\hline SDES & $1,55 \mathrm{a}$ & $0,36 \mathrm{~b}$ & $0,12 \mathrm{~b}$ & $0,24 \mathrm{~b}$ \\
\hline POU & $1,23 \mathrm{~b}$ & $0,51 \mathrm{a}$ & $0,25 \mathrm{a}$ & $0,25 \mathrm{~b}$ \\
\hline AZEV & $1,16 \mathrm{~b}$ & $0,50 \mathrm{a}$ & $0,26 \mathrm{a}$ & $0,24 \mathrm{~b}$ \\
\hline MUC & $1,27 \mathrm{~b}$ & $0,47 \mathrm{a}$ & 0,22 a & $0,25 \mathrm{~b}$ \\
\hline CNA & $1,26 \mathrm{~b}$ & 0,48 a & 0,18 ab & 0,30 a \\
\hline NFO & $1,12 \mathrm{~b}$ & $0,51 \mathrm{a}$ & $0,26 \mathrm{a}$ & $0,24 \mathrm{~b}$ \\
\hline \multirow[t]{2}{*}{$\mathrm{CV}(\%)$} & 9,49 & 13,84 & 28,03 & 8,05 \\
\hline & \multicolumn{4}{|c|}{$0,05-0,10 \mathrm{~m}$} \\
\hline MFP & $1,45 \mathrm{~b}$ & $0,42 \mathrm{a}$ & $0,19 \mathrm{a}$ & $0,23 \mathrm{c}$ \\
\hline SDES & $1,61 \mathrm{a}$ & $0,37 \mathrm{~b}$ & $0,12 \mathrm{~b}$ & $0,27 \mathrm{ab}$ \\
\hline POU & $1,47 \mathrm{ab}$ & $0,39 \mathrm{ab}$ & $0,17 \mathrm{ab}$ & $0,22 \mathrm{c}$ \\
\hline AZEV & $1,50 \mathrm{ab}$ & $0,37 \mathrm{~b}$ & $0,14 \mathrm{ab}$ & $0,23 \mathrm{c}$ \\
\hline MUC & $1,48 \mathrm{ab}$ & $0,41 \mathrm{ab}$ & $0,17 \mathrm{ab}$ & $0,23 \mathrm{c}$ \\
\hline CNA & $1,44 \mathrm{~b}$ & $0,40 \mathrm{ab}$ & $0,13 \mathrm{~b}$ & 0,28 a \\
\hline NFO & $1,52 \mathrm{ab}$ & $0,38 \mathrm{ab}$ & $0,15 \mathrm{ab}$ & $0,23 \mathrm{~d}$ \\
\hline \multirow[t]{2}{*}{$\mathrm{CV}(\%)$} & 4,66 & 7,31 & 23,31 & 5,05 \\
\hline & \multicolumn{4}{|c|}{$0,10-0,15 \mathrm{~m}$} \\
\hline MFP & $1,49^{\mathrm{ns}}$ & $0,39^{\mathrm{ns}}$ & $0,16^{\mathrm{ns}}$ & $0,24 \mathrm{ab}$ \\
\hline SDES & 1,56 & 0,38 & 0,14 & $0,24 \mathrm{ab}$ \\
\hline POU & 1,50 & 0,38 & 0,15 & $0,23 \mathrm{~b}$ \\
\hline AZEV & 1,55 & 0,37 & 0,14 & $0,24 \mathrm{ab}$ \\
\hline MUC & 1,48 & 0,38 & 0,15 & $0,23 \mathrm{ab}$ \\
\hline CNA & 1,56 & 0,37 & 0,11 & $0,26 \mathrm{a}$ \\
\hline NFO & 1,53 & 0,38 & 0,16 & $0,22 \mathrm{~b}$ \\
\hline \multirow[t]{2}{*}{$\mathrm{CV}(\%)$} & 3,37 & 8,30 & 22,60 & 5,63 \\
\hline & \multicolumn{4}{|c|}{$0,15-0,20 \mathrm{~m}$} \\
\hline MFP & $1,53^{\mathrm{ns}}$ & $0,38^{\mathrm{ns}}$ & $0,15^{\mathrm{ns}}$ & $0,24^{\mathrm{ns}}$ \\
\hline SDES & 1,49 & 0,38 & 0,14 & 0,24 \\
\hline POU & 1,48 & 0,37 & 0,13 & 0,24 \\
\hline AZEV & 1,50 & 0,39 & 0,16 & 0,24 \\
\hline MUC & 1,57 & 0,37 & 0,14 & 0,24 \\
\hline CNA & 1,50 & 0,38 & 0,13 & 0,24 \\
\hline NFO & 1,50 & 0,39 & 0,16 & 0,23 \\
\hline $\mathrm{CV}(\%)$ & 4,14 & 6,98 & 21,02 & 5,37 \\
\hline
\end{tabular}

(1) MFP: milho + feijão-de-porco/soja; SDES: solo descoberto; POU: milho/pousio/soja; AZEV: milho/azevém + ervilhaca/soja; MUC: milho + mucuna/soja; CNA: campo nativo; NFO: milho/ nabo forrageiro/soja. Adaptado de Debarba (1993). Médias seguidas pela mesma letra, na mesma coluna e profundidade, não diferem entre si pelo teste de Tukey $(p<0,05)$. ${ }^{\text {ns }}$ Diferenças não significativas.

A variabilidade encontrada nos valores de Ds pode ser atribuída ao tempo de utilização dos sistemas de culturas, bem como à semelhança entre seus sistemas radiculares, pois, segundo Cruz et al. (2003), três anos de adoção do sistema plantio direto não é suficiente para determinar alterações nas propriedades físicas de um Argissolo Vermelho semelhante ao do presente estudo. Bertol et al. (2004) também sugerem que os 
efeitos de sistemas de culturas em semeadura direta envolvendo pousio e adubos verdes no inverno devem se manifestar após transcorridos vários anos de adoção. Como, no presente estudo, todas as práticas de manejo das culturas foram efetuadas manualmente, sem tráfego de máquinas, constata-se que houve consolidação natural da camada superficial do solo em comparação com a situação ao final do primeiro ano de experimentação, em razão de o solo ter sido submetido ao preparo convencional para instalação do experimento. No campo nativo observou-se redução da Ds entre 1991 e 2007, a qual é atribuída ao fato de, no momento da instalação do experimento, as parcelas correspondentes terem sido trafegadas intensamente por máquinas agrícolas, sendo a partir de então isoladas e mantidas livres de tráfego. No período transcorrido entre a primeira e a segunda coleta, o sistema radicular das espécies vegetais atuou no sentido de recuperar a condição física anterior ao tráfego das máquinas.

A porosidade do solo, um ano após a instalação do experimento, assim como a DS, também não foi alterada pelos sistemas de culturas estudados, nas duas profundidades avaliadas (Quadro 1). $\mathrm{Na}$ avaliação realizada 16 anos depois, alterações significativas foram encontradas. Os tratamentos NFO e POU apresentaram os menores valores de microporosidade do solo na camada de 0,10-0,15 m, os quais diferiram apenas do CNA (Quadro 2). Nas camadas de 0,0-0,05 e 0,05-0,10 m, o solo descoberto apresentou o menor valor de porosidade total, porém na camada de 0,05-0,10 m diferiu apenas do tratamento que incluiu feijão-de-porco em seu sistema de culturas. A macroporosidade da camada superficial (0,00-0,05 m) também foi inferior no solo descoberto (SDES), sendo semelhante ao solo sob campo nativo, que não diferiu dos demais. Mesmo na situação em que o solo permanece exposto ao impacto das gotas da chuva, os valores encontrados situam-se acima do limite crítico de macroporosidade, em que o valor de $0,10 \mathrm{dm}^{3} \mathrm{dm}^{-3}$ seria o limite crítico em que começaria a haver problemas de aeração para as raízes das plantas, reduzindo a continuidade de poros e a permeabilidade do solo (Silva et al., 1994). Os valores de densidade, bem como os de porosidade (macro, micro e total) (Quadro 2), concordam com os que Cruz et al. (2003) encontraram em um Argissolo Vermelho semelhante ao do presente estudo. Bertol et al. (2004) também não encontraram diferenças significativas na porosidade do solo ao avaliarem sistemas de sucessão e rotação de culturas em semeadura direta, comparadas a um campo nativo. Os autores associaram as alterações na porosidade do solo às ocorridas na sua densidade, e, para que estas se manifestem, é necessário um longo período de utilização dos sistemas de culturas.

A avaliação da resistência mecânica do solo à penetração (RP) mostrou diferenças significativas entre os tratamentos (Figura 1a). Da mesma maneira, a umidade gravimétrica do solo (Ug) também diferiu significativamente (Figura 1b). Por realizar leituras a cada $0,01 \mathrm{~m}$, a RP consegue identificar com maior precisão as camadas compactadas do solo, e isso ficou evidenciado nos três primeiros centímetros do tratamento SDES, diferindo significativamente dos demais. Da camada compreendida entre $0,05 \mathrm{~m}$ e $0,25 \mathrm{~m}$, o tratamento NFO apresentou valores mais elevados de resistência à penetração, porém não diferindo estatisticamente dos demais, com exceção do MFP, que obteve os menores valores até $0,16 \mathrm{~m}$, e POU e MUC, nas profundidades de 0,16, 0,17 e 0,18 m, respectivamente. Kubota et al. (2005) encontraram incremento nos valores de Ds e RP, na camada superficial do solo, após cultivo de nabo forrageiro, atribuindo o resultado à pressão lateral exercida pelo crescimento expressivo de sua raiz principal. Ao contrário do encontrado neste trabalho, Prado et al. (2002) concluíram que a utilização de pousio por cinco anos comprometeu a qualidade do solo, avaliada pela resistência à penetração, em comparação com o solo

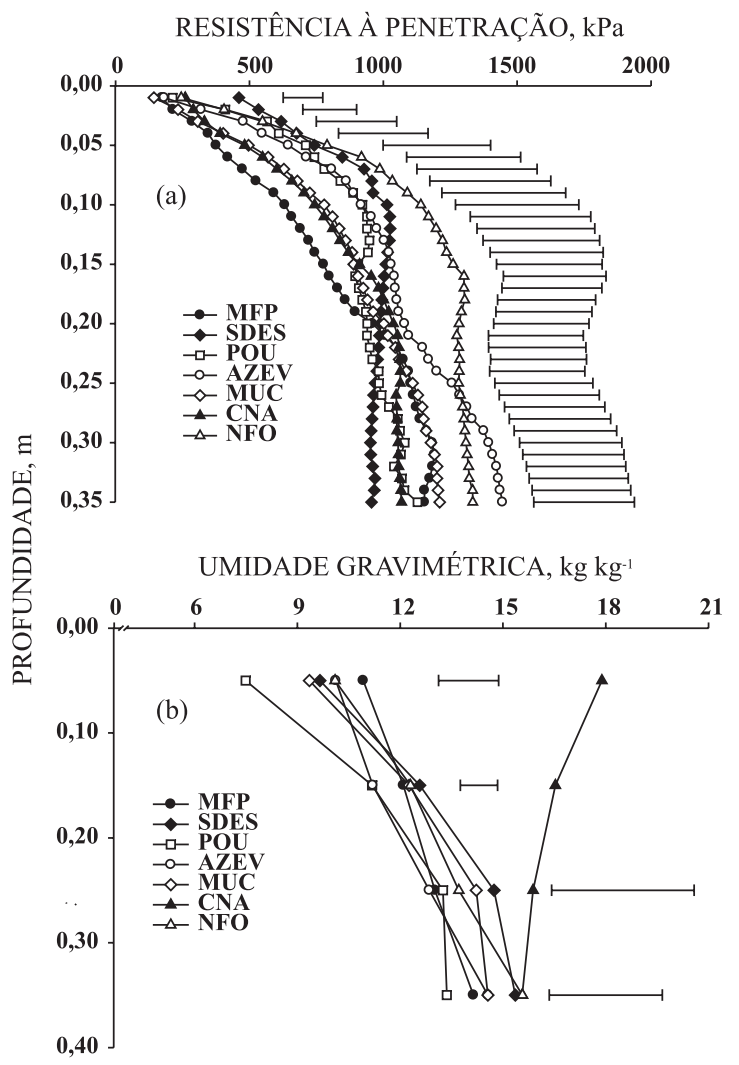

Figura 1. Resistência do solo à penetração (a) e umidade gravimétrica (b) em um Argissolo Vermelho submetido a diferentes sistemas de culturas em plantio direto, após 16 anos de experimentação. (MFP: milho + feijão-de-porco/ soja; SDES: solo descoberto; POU: milho/pousio/ soja; AZEV: milho/azevém + ervilhaca/soja; MUC: milho + mucuna/soja; CNA: campo nativo; NFO: milho/nabo forrageiro/soja). As barras horizontais correspondem à diferença mínima significativa pelo teste de Tukey $(p<0,05)$. 
sob cultivo intensivo, não importando o sistema de preparo utilizado. De 0,20 até $0,28 \mathrm{~m}$ todos os tratamentos foram equivalentes. De maneira geral, os valores encontrados para resistência do solo à penetração $(<1.500 \mathrm{kPa})$ não são comprometedores para o desenvolvimento radicular das plantas (Taylor et al., 1966; Lipiec \& Hatano, 2003). No momento da avaliação da RP, o solo mantido em pousio (POU) apresentou o menor conteúdo de água na camada de 0,0-0,10 m, e na camada de 0,10-0,20 m se assemelhou ao tratamento NFO, diferindo dos demais. Nas maiores profundidades, os tratamentos apresentaram mesma umidade gravimétrica (Figura 1b). A importância de se conhecer a umidade gravimétrica no momento da avaliação de RP deve-se ao fato de existir estreita relação entre as duas características, já demonstrada anteriormente no mesmo solo por Riquelme (2004). O maior conteúdo de água foi encontrado no campo nativo e pode ser decorrente da densa e permanente cobertura do solo proporcionada por elas, que causariam uma espécie de obstáculo ao processo evaporativo da atmosfera em períodos de estresse hídrico. Conclusão semelhante pode ser atribuída ao valor encontrado para a umidade gravimétrica do solo descoberto (SDES), que não foi estatisticamente diferente dos valores encontrados em MFP, AZEV, MUC e NFO. Da mesma maneira que o selamento encontrado na superfície desse tratamento dificulta a infiltração de água no solo (Figura 3), pode também prejudicar o processo contrário, de evaporação de água do solo para a atmosfera, como constatado por Gonzáles \& Alves (2005).

A taxa de infiltração de água no solo é uma das avaliações que melhor distinguem os tratamentos avaliados (Figura 2) e tem sido utilizada como parâmetro de avaliação da qualidade do solo (Amado et al., 2007; Lanzanova et al., 2007). Os valores do coeficiente de variação encontrados - de 65, 75, 64, $60,60,43,37$ e $44 \%$, para os tempos de $5,10,15,20$, 30, 60, 90 e $120 \mathrm{~min}$, respectivamente-, embora altos, são considerados normais para esse tipo de determinação (Warrick \& Nielsen, 1980). A umidade gravimétrica do solo, no momento da avaliação da taxa de infiltração de água, na camada de 0-0,10 m, foi de 0,154, 0,136, 0,138, 0,159, 0,156, 0,204 e 0,153 kg kg-1, para os tratamentos MFP, SDES, POU, AZEV, MUC, CNA, NFO, respectivamente.

Os menores valores foram encontrados nos tratamentos SDES e CNA desde o tempo inicial até o tempo final da avaliação; estes não diferiram significativamente entre si em nenhum dos tempos avaliados e foram semelhantes aos do tratamento POU nos tempos de 5, 10 e 20 min. Segundo a classificação da infiltração proposta por USDA (1998), as taxas no solo descoberto e no campo nativo $\left(7,3\right.$ e $6,4 \mathrm{~mm} \mathrm{~h}^{-1}$, respectivamente) são consideradas lentas (de 1,5 a $15 \mathrm{~mm} \mathrm{~h}^{-1}$ ), enquanto nos demais tratamentos, incluindo o pousio, são consideradas moderadas (de 15 a $51 \mathrm{~mm} \mathrm{~h}^{-1}$ ). Baixas taxas de infiltração de água em campo nativo podem ocorrer devido à densidade

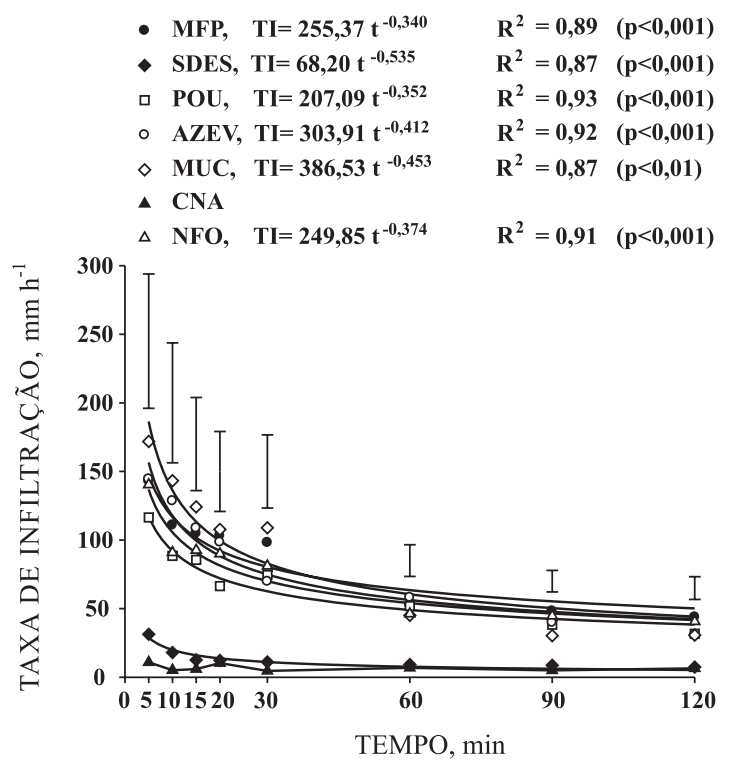

Figura 2. Taxa instantânea de infiltração de água em um Argissolo Vermelho submetido a diferentes sistemas de culturas em plantio direto, após 16 anos de experimentação. (MFP: milho + feijãode-porco/soja; SDES: solo descoberto; POU: milho/pousio/soja; AZEV: milho/azevém + ervilhaca/soja; MUC: milho + mucuna/soja; CNA: campo nativo; NFO: milho/nabo forrageiro/soja). As barras verticais correspondem à diferença mínima significativa pelo teste de Tukey $(\mathrm{p}<0,05)$.

do solo nessas áreas, principalmente na camada de 0,0-0,05 m de profundidade, no caso, por causa de tráfego de máquinas e, naturalmente, em razão do pisoteio animal, com destaque para os casos em que ocorre superpastejo e queimada, sem permanecerem resíduos vegetais sobre o solo e sem possibilidade de as forrageiras se recuperarem adequadamente (Quadro 1). Também, nessa camada, há redução da macroporosidade do solo no tratamento em que este é mantido descoberto (SDES) e no campo nativo (CNA). Como esses poros constituem-se no caminho preferencial para a infiltração da água no solo (Bertol et al., 2000, 2001), as médias ficaram abaixo daquelas dos demais sistemas de culturas. Mesmo por razões distintas, o comportamento semelhante quanto à infiltração de água dos tratamentos SDES e CNA poderia levar a inferir erroneamente que não há necessidade de cobertura permanente do solo para a manutenção de suas propriedades físicas em níveis adequados. No campo nativo a água tem mais dificuldade de infiltrar, pelo fato de que boa parte de seus macroporos está preenchida por raízes, porém, ao mesmo tempo, essa água tem maior dificuldade em escoar na superfície, em razão da elevada e permanente cobertura do solo.

No solo descoberto, o processo de selamento superficial dos poros do solo faz com que a água infiltre com dificuldade (Alves \& Cabeda, 1999), resultando 
em menor retenção e armazenamento e maior escoamento superficial (Debarba, 1993). O tratamento POU, onde foram efetuados apenas cultivos no ciclo de verão, situou-se intermediariamente aos tratamentos que utilizaram adubos verdes tanto de verão quanto de inverno a partir do tempo de $30 \mathrm{~min}$ de avaliação, não diferindo estatisticamente dos demais tratamentos.

Assim como observado na avaliação da densidade e porosidade do solo (Quadro 2), cujos valores da camada superficial apresentam certa correlação com a infiltração, os sistemas de culturas que incluíram os adubos verdes de verão feijão-de-porco (MFP) e mucuna (MUC) nas entrelinhas do milho e em rotação com a soja apresentaram os valores mais elevados para a taxa inicial de infiltração de água até os 30 min de avaliação, em comparação com os demais sistemas de culturas (Figura 2). Aproximando-se da taxa básica de infiltração de água no solo, o que ocorre nos tempos finais de avaliação (de 90 e $120 \mathrm{~min}$ ), os sistemas de culturas MFP e NFO tenderam a apresentar maior média na taxa de infiltração instantânea, em relação aos demais tratamentos.

A figura 3 apresenta a relação entre a taxa de infiltração de água e a macroporosidade do solo média da camada de $0,0-0,20 \mathrm{~m}$, para os tratamentos avaliados. Com base na relação ajustada aos pontos experimentais, para uma macroporosidade de $0,12 \mathrm{dm}^{3} \mathrm{dm}^{-3}$, estima-se uma taxa de infiltração de água de $40 \mathrm{~mm} \mathrm{~h}^{-1}$, porém, ao se aumentar duas vezes o valor da macroporosidade, obtém-se aproxi-

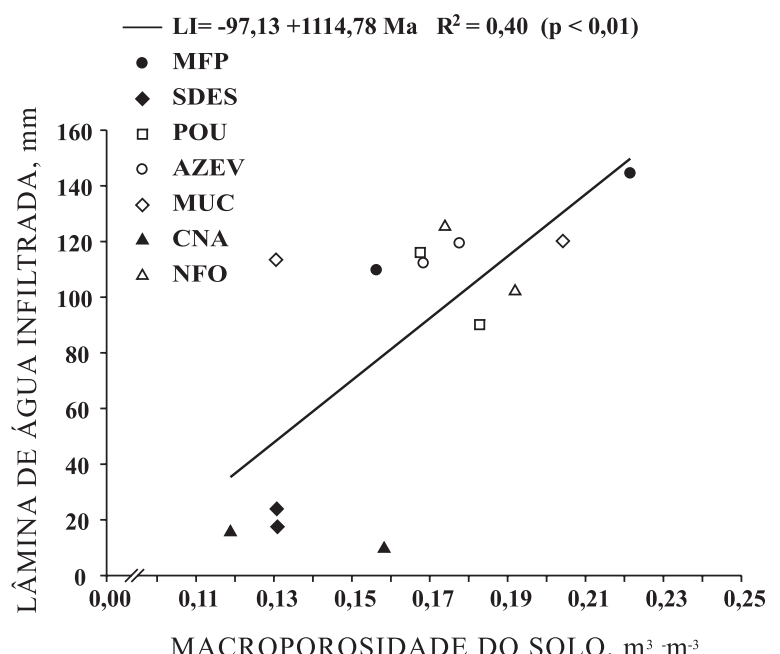

Figura 3. Relação entre macroporosidade média da camada de 0,0-0,20 $\mathrm{m}$ e a lâmina total de água infiltrada em um Argissolo Vermelho submetido a diferentes sistemas de culturas em plantio direto, após 16 anos de experimentação. (MFP: milho + feijão-de-porco/soja; SDES: solo descoberto; POU: milho/pousio/soja; AZEV: milho/azevém + ervilhaca/soja; MUC: milho + mucuna/soja; CNA: campo nativo; NFO: milho/ nabo forrageiro/soja). madamente incremento de três vezes no valor da taxa de infiltração. Como pode ser observado, a infiltração de água no solo é influenciada pelos valores da macroporosidade do solo, ou seja, dos poros com diâmetro maior que $50 \mu \mathrm{m}$, como já relatado por outros autores (Lanzanova et al., 2007; Nicoloso et al., 2008a). Poros ou canais deixados no solo após a senescência do sistema radicular das plantas de cobertura favorecem o incremento da macroporosidade do solo, caminho preferencial para a infiltração de água, destacando-se espécies como o nabo forrageiro (Sasal \& Andriulo, 2005), que possuem raízes vigorosas e agressivas, rompendo inclusive camadas compactadas que outras espécies de plantas não conseguiriam (Reinert et al., 2008).

A relação $\left(R^{2}=0,40, p<0,01\right)$ entre a macroporosidade e a infiltração de água, no presente estudo, embora não tão elevada, concorda com o anteriormente reportado por Nicoloso et al. (2008a) em um Latossolo $\left(\mathrm{R}^{2}=0,82, \mathrm{p}<0,01\right)$ e por Sasal \& Andriulo (2005) $\left(\mathrm{R}^{2}=0,70, \mathrm{p}<0,01\right)$ em um Argissolo, reforçando a importância de uma elevada quantidade e continuidade de macroporos no solo para a manutenção de elevadas taxas de infiltração de água e diminuição de riscos potenciais de enxurrada.

\section{CONCLUSÕES}

1. O solo mantido permanentemente descoberto apresentou degradação física, expressa pelo aumento da densidade do solo e resistência mecânica à penetração, e redução da macroporosidade e da taxa de infiltração de água no solo.

2. O uso de culturas de cobertura foi eficiente em manter as condições físicas do solo favoráveis ao desenvolvimento vegetal, na camada de 0,0-0,10 m de profundidade, com destaque para as leguminosas tropicais mucuna e feijão-de-porco.

3. O sistema de semeadura direta na ausência de tráfego animal e operações com máquinas agrícolas e na presença de culturas de cobertura de inverno e verão foi eficiente em manter a qualidade física do solo.

4. A taxa de infiltração de água no solo mostrou relação linear e diretamente proporcional com a percentagem de macroporos do solo.

\section{LITERATURA CITADA}

ALVES, M.C. \& CABEDA, M.S.V. Infiltração de água em um Podzólico Vermelho-Escuro sob dois métodos de preparo, usando chuva simulada com duas intensidades. R. Bras. Ci. Solo, 23:753-761, 1999.

AMADO, T.J.C.; CONCEIÇÃO, P.C.; BAYER, C. \& ELTZ, F.L.F. Qualidade do solo avaliada pelo "Soil Quality Kit Test" em dois experimentos de longa duração no Rio Grande do Sul. R. Bras. Ci. Solo, 31:109-121, 2007. 
BERTOL, I.; ALBUQUERQUE, J.A.; LEITE, D.; AMARAL, A.J. \& ZOLDAN JUNIOR, W.A. Propriedades físicas do solo sob preparo convencional e semeadura direta em rotação e sucessão de culturas, comparadas às do campo nativo. R. Bras. Ci. Solo, 28:155-163, 2004.

BERTOL, I.; BEUTLER, J.F.; LEITE, D. \& BATISTELA, O. Propriedades físicas de um Cambissolo Húmico afetadas pelo tipo de manejo do solo. Sci. Agric., 58:555-560, 2001.

BERTOL, I.; SCHICK, J.; MASSARIOL, J.M.; REIS, E.F. \& DILLY, L. Propriedades físicas de um Cambissolo Húmico álico afetadas pelo manejo do solo. Ci. Rural, 30:91-95, 2000 .

BOLLIGER, A. et al. Taking stock of Brazilian"zero-till revolution": A review of landmark research and farmer's practice. Adv. Agron., 91:47-110, 2006.

BRASIL. Ministério da Agricultura. Departamento Nacional de Pesquisa Agropecuária. Divisão de Pesquisa Pedológica. Levantamento de reconhecimento de solos do estado do Rio Grande do Sul. Recife, 1973. 431p. (Boletim Técnico, 30)

CINTRA. F. \& MIELNICZUK, J. Potencial de algumas espécies vegetais para a recuperação de solos com propriedades físicas degradadas. R. Bras. Ci. Solo, 7:197-201, 1983.

COMISSÃO DE FERTILIDADE DO SOLO - CFSRS/SC Manual de adubação e calagem para os estados do Rio Grande do Sul e Santa Catarina. 10.ed. Porto Alegre, Sociedade Brasileira de Ciência do Solo - Núcleo Regional Sul; Embrapa/CNPT, 2004. 400p.

CRUZ, A.C.R.; PAULETTO, E.A.; FLORES, C.A. \& SILVA, J.B. Atributos físicos e carbono orgânico de um Argissolo Vermelho sob sistemas de manejo. R. Bras. Ci. Solo, 27:1105-1112, 2003.

DEBARBA, L. Sistemas de produção de milho adaptados à conservação do solo. Santa Maria, Universidade Federal de Santa Maria, 1993. 150p. (Tese de Mestrado).

EMPRESA BRASILEIRA DE PESQUISA AGROPECUÁRIA . EMBRAPA. Centro Nacional de Pesquisa de Solos. Sistema brasileiro de classificação de solos. Brasília, 1999. $412 \mathrm{p}$.

EMPRESA BRASILEIRA DE PESQUISA AGROPECUÁRIA EMBRAPA. Centro Nacional de Pesquisa de Solos. Manual de métodos de análise de solos. 2.ed. Rio de Janeiro, 1997. 212p.

FOLONI, J.S.S.; LIMA, S.L. \& BULL, L.T. Crescimento aéreo e radicular da soja e de plantas de cobertura em camadas compactadas de solo. R. Bras. Ci. Solo, 30:49-57, 2006.

FRYE, W.W.; EBELHAR, S.A.; MURDOCK, L.W. \& BEVINS, R.L. Soil erosion effects on properties and productivity of two Kentucky soils. Soil Sci. Soc. Am. J., 46:1051-1055, 1982.

GONZÁLES, A.P. \& ALVES, M.C. Armazenamento de água e densidade do solo sob três condições de superfície, em um Cambissol gleico de Lugo, Espanha. R. Bras. Eng. Agric. Amb., 9:45-50, 2005.
KUBOTA, A.; HOSHIBA, K. \& BORDON, J. Green-manure turnip of soybean based no-tillage farming systems in eastern Paraguay. Sci. Agric., 62:150-158, 2005.

LAL, R. \& VANDOREN, D. Influence of 25 years of continuous corn by three tillage methods on water infiltration of two soils in Ohio. Soil Till. Res., 16:71-74, 1990.

LANZANOVA, M.E. Atributos físicos do solo em sistemas de culturas sob plantio direto na integração lavoura-pecuária. Santa Maria, Universidade Federal de Santa Maria, 2005. 132p. (Tese de Mestrado).

LANZANOVA, M.E.; NICOLOSO, R.S.; LOVATO, T.; ELTZ, F.L.F; AMADO, T.J.C. \& REINERT, D.J. Atributos físicos do solo em sistemas de integração lavoura-pecuária sob plantio direto. R. Bras. Ci. Solo. 31:1131-1140, 2007.

LIPIEC, J. \& HATANO, R. Quantification of compaction effects on soil physical properties and crop growth. Geoderma, 116:107-136, 2003.

NICOLOSO, R.S.; AMADO, T.J.C.; SCHNEIDER, S.; LANZANOVA, M.E.; GIRARDELLO, V.C. \& BRAGAGNOLO, J. Eficiência da escarificação mecânica e biológica na melhoria dos atributos físicos de um Latossolo muito argiloso e no incremento do rendimento de soja. R. Bras. Ci. Solo. 32:1735-1742, 2008a.

NICOLOSO, R.S.; LOVATO, T.; AMADO, T.J.C.; BAYER, C. \& LANZANOVA, M.E. Balanço de carbono orgânico no solo sob integração lavoura-pecuária no sul do Brasil. R. Bras. Ci. Solo. 32:2425-2433, 2008b.

PIERCE, F.J.; FORTIN, M.C. \& STATON, M.J. Periodic plowing effects on soil properties in a no-till farming system. Soil Sci. Soc. Am. J., 58:1782-1787, 1994.

PRADO, R.M.; ROQUE, C.G. \& SOUZA, Z.M. Sistemas de preparo e resistência à penetração e densidade de um Latossolo Vermelho eutrófico em cultivo intensivo e pousio. Pesq. Agropec. Bras., 37:1795-1801, 2002.

REICHERT, J.M.; REINERT, D.J. \& BRAIDA, J.A. Qualidade dos solos e sustentabilidade de sistemas agrícolas. Ci. Amb., 27:29-48, 2003.

REINERT, D.J.; ALBUQUERQUE, J.A.; REICHERT, J.M.; AITA, C. \& ANDRADA, M.M.C. Limites críticos de densidade do solo para o crescimento de raízes de plantas de cobertura em Argissolo Vermelho. R. Bras. Ci. Solo, $32: 1805-1816,2008$.

RIQUELME, U.R.B. Propriedades físicas e hídricas do solo em sistemas de manejo do feijoeiro. Santa Maria, Universidade Federal de Santa Maria, 2004. 78p. (Tese de Mestrado).

ROSOLEM, C.A.; FOLONI, J.S.S. \& TIRITAN, C.S. Root growth and nutrient accumulation in cover crops as affected by soil compaction. Soil Till. Res., 65:109-115, 2002 .

SASAL, M.C. \& ANDRIULO, A.E. Câmbios en la porosidad edafica bajo siembra directa por la introducción de Raphanus sativus L. (nabo forragero). R. Invest. Agropec., 34:131-150, 2005. 
SILVA, A.A.; SILVA, P.R.F.; SUHRE, E.; ARGENTA, G.; STRIEDER, M. \& RAMBO, L. Sistemas de coberturas de solo no inverno e seus efeitos no rendimento de grãos de milho em sucessão. Ci. Rural, 37:928-935, 2007.

SILVA, A.P.; KAY, B.D. \& PERFECT, E. Characterization of the least limiting water range. Soil Sci. Soc.Am. J., 58:1775-1781, 1994.

SILVA, C.L. \& KATO, E. Efeito do selamento superficial na condutividade hidráulica saturada da superfície de um solo sob cerrado. Pesq. Agropec. Bras., 2:213-220, 1997.

TAYLOR, H.M.; ROBERTSON, G.M. \& PARKER, J.J. Soil strength root penetration relations for medium to coarse textured soil materials. Soil Sci., 102:18-22, 1966.
USDA-ARS. Soil quality test kit guide. Washington, Soil Quality Institute, 1998. 82p.

WARRICK A.W. \& NIELSEN, D.R. Spatial variability of soil physical properties in the field. In: HILLEL, D., ed. Application of soil physics. New York, Academic Press, 1980.

WILLIANS, S.M. \& WEIL, R.R. Crop cover root channels may alleviate soil compaction effects on soybean crop. Soil Sci. Soc. Am. J., 68:1403-1409, 2004. 